\title{
A General Framework Protocol for Indoor and Outdoor Location-Based Service
}

Yan Li , Li-ping Zhu*

Information Engineering College,Minzu University of China,Beijing, China

461350652@qq.com zlp6681@sina.com*

Keywords-locating data protocol; indoor and outdoor; location-based service

\begin{abstract}
To satisfy the requirement of the increasing location-based service, there have been a lot of solutions on indoor and outdoor locating. The general data protocols for transferring outdoor location data are also mature. However, there still lack general data format and transferring protocol for indoor or hybrid indoor-outdoor location. In this paper, a general framework protocol for indoor and outdoor positioning, which includes locating data format and the transfer frame format, is proposed. The data tables and frame format of the protocol are presented and examples on how to use them are given. It is a protocol aimed to be used by different mobile devices sending locating data to the locating server. The design idea of this protocol is to use various positioning methods available at present, and different kinds of data should be combined easily according to different environment identified by the mobile device.
\end{abstract}

\section{Introduction}

With Location-based Service (LBS) fast becoming one of the standard features in mobile devices, an increasing number of studies concentrate on personal navigation for both outdoor and indoor environments [5-7]. With the aid of the Global Navigation Satellites Systems (GNSSs), e.g., GPS and BeiDou, mobile devices greatly facilitate the end users' outdoor activities. However, GNSS-based positioning technologies are not primarily suited for use in urban canyons or indoors due to the nature of GNSS design. They are continuing to struggle indoors, because of well-known problems such as the weak signal or non line-of-sight (NLOS) conditions between mobile users and satellites [1]. To address positioning and navigation in GNSS-degraded denied areas, various technologies are broadly researched, e.g., [2]. Various positioning technologies for indoor environments are proposed, including radio frequency identification (RFID), infrared, Bluetooth, Zigbee, Ultra-wide Bandwidth (UWB) and Wi-Fi [3]. The multi-network positioning system proposed in [4] improves the availability and reliability of navigation and positioning. Windows Phone, Apple iPhone and Google's Location Based Service (LBS)-enabled Android operating systems have allowed developers to introduce LBS to millions of smart device consumers. Many LBSs perform location functions by means of location data or positioning correlated parameters transfer between the smart device and the location server, e.g., gpsOne location system and Google network location system. These systems have their own location request and response data format, data field definition and transfer protocols [8]. Emerging indoor location technologies such as sensors aided positioning and RFID location make more and versatile location applications possible.

Although many indoor location technologies have standards, there are still few transfer protocols in support of location computations. Different indoor location systems often have their own private protocols for location applications, which are incompatible with each other. To the best of the authors' knowledge, a unified transfer protocol for various indoor location applications is still lacking. Considering the future possibilities and increasing requirements for various hybrid location applications, there is an urgent need for a widely applied protocol on transferring all the locating correlated data and parameters using a general and common format.

In this paper, a solution on the general locating protocol is introduced, which aims at adapting for all kinds of devices and combining different ways of positioning data and parameters. The rest of the paper is structured as follows. The architecture of 4 location data tables are introduced in Section II. The proposed frame format of the protocol is presented in Section III. In Section IV, two 
examples on how the protocol transfers data and identifies environment are given. Finally, some problems about this work are discussed in the last Section.

\section{Data Format of General Locating Protocol}

The design of location data structure and tables references the RTCM STANDARD 10403.1 for DIFFERENTIAL GNSS SERVICES - VERSION 3 [9].

\section{A. Basic Message Types}

First, the Basic Message Types supporting different indoor and outdoor location service are defined as is shown in Table I. There is no coupling between any of the two message types. Every Basic Message only contains the minimum data for a particular positioning pattern but can be combined with each other for various purposes. To avoid confliction with RTCM, the message type is numbered from 200100. There's a gap of 100 between adjacent numbers to allow to use a specific message type repeatedly but fulfilled with different data.

\section{B. Basic Message Tables}

Then, each basic message type is defined in a separate table called Basic Message table, which defines the specific content of a Basic Message Type. Every message consists of four fields, in which DATA FIELD contains the parameters or data used for positioning. Each item in DATA FIELD is indexed by a DF NUMBER, and the data type and the length of each item are shown in Data TYPE and NO. OF BITS, respectively. Each basic message is designed to include the minimum data fields for a particular locating method and can be combined in different forms according to different hybrid location techniques. Take outdoor location and indoor location message as examples.

Two messages are defined for GNSS locating data. One of the messages contains four kinds of GNSS data in a unified form, and the other is only for BNSS location data. Table II shows the contents of outdoor GNSS message 200100. We use four indicators for each GNSS respectively with the location data filling in the same data field named Antenna Reference Point ECEF-X, Y, Z, which have been used to represent location in RTCM 10403.1 STANDARD. Thus, this message type could be used repeatedly for different GNSS.

table i. Basic Message TyPe

\begin{tabular}{|c|c|c|c|}
\hline $\begin{array}{l}\text { Message } \\
\text { Type }\end{array}$ & Message Name & $\begin{array}{l}\text { No. of } \\
\text { Bits }\end{array}$ & Note \\
\hline 200100 & $\begin{array}{l}\text { Outdoor } \\
\text { GPS/GLONASS/Galileo/BNSS } \\
\text { /Multi-Satellite-System } \\
\text { Locating }\end{array}$ & 176 & $\begin{array}{l}\text { Integrated } 4 \text { GNSS data in one form that could } \\
\text { provide GNSS independently or use this type } \\
\text { repeatedly to combine them locating result. }\end{array}$ \\
\hline 200200 & Outdoor BNSS Only & 124 & Provide BNSS locating data. \\
\hline 200300 & $\begin{array}{ll}\text { Outdoor-Indoor } & \text { transfer } \\
\text { operating data } & \\
\end{array}$ & 60 & $\begin{array}{l}\text { This type is used to judge the environment of the } \\
\text { location and the device hardware. }\end{array}$ \\
\hline 200400 & Wi-Fi RSSI & 81 & Content of a specific Wi-Fi AP’s Mac and RSSI. \\
\hline 200500 & FM Multi-Data Locating & 65 & $\begin{array}{lccc}\text { Include } & \text { RSSI, SNR, } & \text { MULPATH, } & \text { and } \\
\text { FRQOFFEST for locating. } & & \\
\end{array}$ \\
\hline 200600 & Bluetooth RSSI & 80 & Content of a specific Bluetooth AP's Mac and RSSI \\
\hline 200700 & NFC Tag Fixed Point Locating & 97 & Use to transfer the message from NFC Tags. \\
\hline 200800 & ZigBeee Locating Data & 66 & Base on CS20XX positioning method \\
\hline 200900 & UWB TDOA Locating & 88 & $\begin{array}{l}\text { Only provide time information for TDOA } \\
\text { positioning method. } \\
\text { Could use with type } 200100 \text { AOA data together for } \\
\text { 2-way locating. }\end{array}$ \\
\hline 200100 & UWB AOA Locating & 84 & $\begin{array}{l}\text { Only provide time information for } \mathrm{AOA} \\
\text { positioning method. }\end{array}$ \\
\hline
\end{tabular}


TABLE III. CONTENTS OF TYPE 200100: OUTDOOR GPS/GLONASS/GALILEO/BNSS

\begin{tabular}{|l|l|l|l|}
\hline \multicolumn{1}{|c|}{ DATA FIELD } & \multicolumn{1}{c|}{$\begin{array}{c}\text { DF } \\
\text { NUMBER }\end{array}$} & \multicolumn{1}{c|}{$\begin{array}{c}\text { DATA } \\
\text { TYPE }\end{array}$} & \multicolumn{1}{c|}{$\begin{array}{c}\text { NO. OF } \\
\text { BITS }\end{array}$} \\
\hline Message Number & DF901 & uint24 & 24 \\
\hline Reference Station ID & DF002 & uint12 & 12 \\
\hline $\begin{array}{l}\text { Reserved for ITRF Realization } \\
\text { Year }\end{array}$ & DF003 & uint6 & 6 \\
\hline GPS Indicator & DF004 & bit(1) & 1 \\
\hline GLONASS Indicator & DF005 & bit(1) & 1 \\
\hline Galileo Indicator & DF006 & bit(1) & 1 \\
\hline BNSS Indicator & DF011 & bit(1) & 1 \\
\hline $\begin{array}{l}\text { Antenna Reference Point } \\
\text { ECEF-X }\end{array}$ & DF007 & int38 & 38 \\
\hline $\begin{array}{l}\text { Antenna Reference Point } \\
\text { ECEF-Y DF008 }\end{array}$ & int38 & 38 \\
\hline $\begin{array}{l}\text { Antenna Reference Point } \\
\text { ECEF-Z }\end{array}$ & DF009 & int38 & 38 \\
\hline Antenna Height & DF010 & uint16 & 16 \\
\hline TOTAL & & 176 \\
\hline
\end{tabular}

For indoor locating messages, each message only contains the necessary data fields for one specific locating method. Take Wi-Fi locating message 200400 as an example. The Wi-Fi locating method needs MAC and RSSI. So TABLE III includes three data field: Message Number, Wi-Fi MAC and Wi-Fi RSSI. In most case, we need to send more than one AP's information to perform the positioning algorithm required. By increasing Message Number automatically we can transfer different data in the form of the same type. For instance, we need 3 or $5 \mathrm{Wi}$-Fi APs to get enough data and match the fingerprint so we need to use this message type repeatedly with different Message Number. Now we code the Message Number as 200400, 200401, 200402... 200404 and send 5 different AP data in one form of message type in the frame. The 2004 stand for the Message Type. $00,01 \ldots 04$ represent various data.

TABLE IV. CONTENTS OF TyPe 200400 Message

\begin{tabular}{|l|l|l|l|}
\hline \multicolumn{1}{|c|}{ DATA FIELD } & \multicolumn{1}{c|}{$\begin{array}{c}\text { DF } \\
\text { NUMBER }\end{array}$} & \multicolumn{1}{c|}{$\begin{array}{c}\text { DATA } \\
\text { TYPE }\end{array}$} & \multicolumn{1}{c|}{$\begin{array}{c}\text { NO. OF } \\
\text { BITS }\end{array}$} \\
\hline Message Number & DF901 & uint24 & 24 \\
\hline Wi-Fi MAC & DF201 & bit(48) & 48 \\
\hline Wi-Fi RSSI & DF202 & bit(9) & 9 \\
\hline TOTAL & & & 81 \\
\hline
\end{tabular}

\section{Data Fields Tables}

The DF NUMBER in Basic Message Type and Basic Message Tables is defined in the Data Fields Tables, which contain essential data for 10 methods of locating. 4 GNSS data are GPS, GLONASS, Galileo and BNSS. 6 indoor locating data using APs are Wi-Fi, Bluetooth, FM, Zigbee, UWB and NFC. We give part of the table in TABLE IV, in which there are two data fields named DF201 and DF202 respectively, standing for Wi-Fi Mac and Wi-Fi RSSI respectively. These two data fields are widely used in Wi-Fi positioning. Tables.

Also, we define other data fields we needed for the transferring frame structure in the Data Fields 
TABLE V. INSTANCE OF DATA FIELDS TABLE

\begin{tabular}{|l|l|l|l|l|l|}
\hline DF\# & DF Name & DF Range & DF Resolution & Data Type & \multicolumn{2}{|c|}{ Data Field Notes } \\
\hline DF201 & Wi-Fi MAC & $0 \sim 2^{\wedge} 48$ & & bit(48) & $\begin{array}{l}\text { Identifier for a } \\
\text { particular network } \\
\text { adapter }\end{array}$ \\
\hline DF202 & Wi-Fi RSSI & $0 \sim 100$ & & bit(9) & $\begin{array}{l}\text { Received Signal } \\
\text { Strength Indicator. }\end{array}$ \\
\hline
\end{tabular}

\section{Data Type Tables}

Finally, Data Type Tables include all the data type that are used in the Data Fields Tables and define the form and range of these data. TABLE V shows part of a Data Type Table.

TABLE VI. DATA TYPE TABLE

\begin{tabular}{|l|l|l|l|}
\hline \multicolumn{1}{|c|}{$\begin{array}{c}\text { Data } \\
\text { Type }\end{array}$} & \multicolumn{1}{|c|}{ Description } & \multicolumn{1}{c|}{ Range } & \multicolumn{1}{c|}{ Data Type Notes } \\
\hline bit(n) & bit field & 0 or 1, each bit & Reserved bits set to “0” \\
\hline char8(n) & $\begin{array}{l}\text { 8 bit characters, ISO 8859-1 } \\
\text { (not limited to ASCII) }\end{array}$ & character set & $\begin{array}{l}\text { Reserved or unused } \\
\text { characters: [0x00] }\end{array}$ \\
\hline int14 & $\begin{array}{l}\text { 14 bit 2's complement } \\
\text { integer }\end{array}$ & -8192 to +8191 & \\
\hline int16 & $\begin{array}{l}\text { 16 bit 2's complement } \\
\text { integer }\end{array}$ & $\pm 32,767$ & $\begin{array}{l}\text {-32,768 indicates data } \\
\text { not available }\end{array}$ \\
\hline
\end{tabular}

In all, four kinds of tables are defined. They are Basic Message Type, Basic Message, Data Type and Data Fields. The final result of the 4 kinds of tables is basic messages that we will use them independently or combine them for diverse pattern of positioning.

\section{Frame Format of General Locating Protocol}

Considering that this protocol is mainly design for mobile devices sending data to server for locating, we define the General Frame Format as Fig. 1.

General Frame Format includes a series fields and be presented in fixed order. The first field is Frame Control and the last field is Frame Check Sequence (FCS). For different needs, Communicating Environment Field and Message Body only appears in particular frame.

Octets: 4
\begin{tabular}{|l|l|l|l|l|l|}
\hline $\begin{array}{l}\text { Frame } \\
\text { Control- }\end{array}$ & $\begin{array}{l}\text { Communicating } \\
\text { Environment Field }\end{array}$ & Message Body 1 & Message Body 2 & $\begin{array}{l}\text { (more message } \\
\text { type) }\end{array}$ & FCS \\
\hline
\end{tabular}

Figure 1. General frame format.

\section{E. Frame Control Field}

As the first field of general frame, this field contains necessary information which includes Protocol Version, Timestamp, Communication Mode, Number of Message and Power Management. All these data fields have been defined in the Data Fields Tables. Value of Communication Mode field determines whether general frame have locating data or not. The value 0 means that this frame is in identifying mode and no locating data is sent. On the other hands, if the value is 1 , the frame will include locating data rather than identify environment. Fig. 2 shows Frame Control structure.

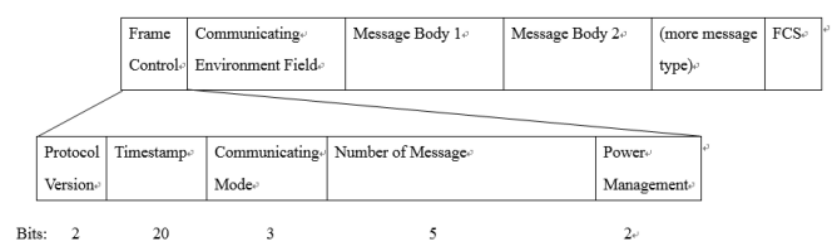

Figure 2. Illustration of the frame control field. 


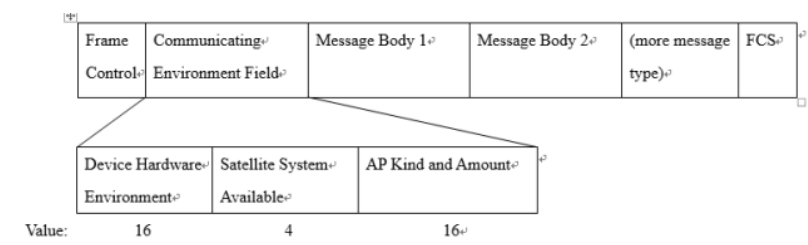

Figure 3. Environment identifying frame.

\section{F. Communicating Environment Field}

As is shown in Fig. 3, Communication Environment field includes data of mobile device's hardware condition and the indoor or outdoor environment. We will give example later to describe how it works.

\section{Examples and Explanations}

Here we will give two examples to show how the frame identify environment and transfer locating data.

\section{G. Identify Environment Frame}

Fig. 4 shows an Environment Identifying Frame. This frame is only for give some data to server for identify hardware condition and environment so this frame contains the Communicating Environment Field but have no message. The specific examples are presented blow.

Fig. 5 is an example of Frame Control. Now the protocol version is 00. Timestamp shows the time is 17:55:24.98 (hhmmssss). Communicating Mode value 0 means this frame aiming for identify rather than transfer data. Power Management is normal.

Fig. 6 is an example of Communicating Environment Field. This field contains 3 data fields: Device Hardware Environment, Satellite System Available, and AP Kind and Amount.

$$
\begin{array}{|l|l|l|}
\hline \begin{array}{l}
\text { Frame } \\
\text { Control } /
\end{array} & \begin{array}{l}
\text { Communicating } \\
\text { Environment Field }
\end{array} & \text { FCS } \\
\hline
\end{array}
$$

Figure 4. Example of frame control.

\begin{tabular}{l|l|l|l|l|}
\begin{tabular}{|l|l|l|} 
Protocol \\
Version
\end{tabular} & Timestamp & $\begin{array}{l}\text { Communicating } \\
\text { Mode }\end{array}$ & Number of Message & $\begin{array}{l}\text { Power } \\
\text { Management }\end{array}$ \\
\hline
\end{tabular}

Figure 5.Example of communicating environment field

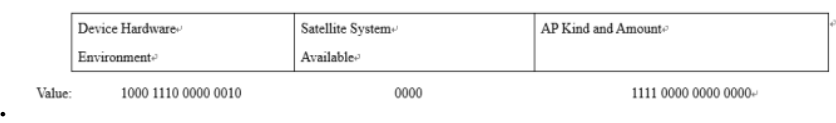

Fig. 6 example of Communicating Environment Field

- Device Hardware Environment

The Device Hardware Environment is defined as a 16-bit value show how much hardware in this device could be used and what the type of this device. As is shown in Fig. 7, every bit of Device Hardware Environment represents a kind of hardware. If the hardware can be used in a specific device, the corresponding bit will be set 1 . If a device does not have this kind of hardware, the bit will be set 0 . The last 2 bits stands for Device Identifier which shows the device type.

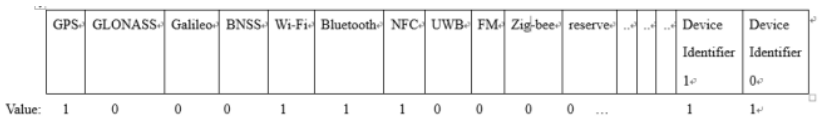

Fig7.Device hardware environment. 
In the example shown in Fig. 8, we know the device has GPS, Wi-Fi, Bluetooth and NFC hardware. This device is identified as consumer electronic like common smart phone.

\begin{tabular}{|l|l|l|l|}
\hline Device Identifier & 00 & 01 & 11 \\
\hline 6 & $\begin{array}{l}\text { professional devices } \\
\text { industry devices }\end{array}$ & $\begin{array}{l}\text { sports devices } \\
\text { N }\end{array}$ & Consumer Electronics \\
\hline
\end{tabular}

Fig8.Device identifier.

- Satellite System Available Indicator

Satellite System Available is defined as a 4-bit value, with every bit representing whether a GNSS is available or not. If the GNSS could receive 4 or more satellites then we assume that this GNSS is available and the bit will set 1 . Fig. 9 shows that none of the 4 GNSS could receive 4 or more signals from satellites so they are not available in this situation.

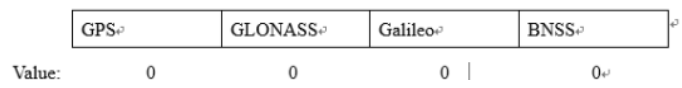

Fig9. Satellite system available indicator.

- AP Kind and Amount

AP Kind and Amount define as 16-bit value as is shown in Fig. 10. Every 4-bit stands for the amount of APs that could be sensed by the mobile device. Considering that 5 APs data which can be used in locating is reasonable, the maximum number is set to 15. If the amount is more than 15 the value still be set to 1111 . Fig. 10 shows that this device can receive 15 or more Wi-Fi APs. No Bluetooth, UWB and FM (as Fig.7 shows, this device not have FM hardware) APs are found.

To sum up all the information above, we know that this is a kind of consumer electronics like smart phones and it contains the basic hardware of a smart phone like Wi-Fi, GPS, Bluetooth and NFC. This device now cannot receive signals from GNSS but could get 7 or more signals from WiFi APs by which the server could judge that this device maybe in a building. Also the server gets the protocol version, the time when the frame is sent and the power state in this frame.

When we need to use seamless navigation system, we can refresh the data field of Satellite System Available and AP Kind and Amount and resend the identifying frame in some frequency to know whether the device is indoor or outdoor.

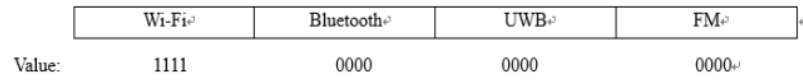

Fig10. AP kind and amount.

\section{H. Transfer Frame}

Fig. 11 shows a transfer frame with 5 messages in one frame. This frame does not contain Communicating Environment Field but can include it if needed. These messages are of the same type 2004 that is designed to transfer Wi-Fi information but they contain 5 different Wi-Fi AP data.

Fig. 12 shows a frame control example which gives the information like Protocol Version, Timestamp and Power Management, but Communicating Mode is set to 1 meaning that this frame will transfer messages and the frame contain 5 messages. So the Number of Message is 5.

\begin{tabular}{|l|l|l|l|l|l|l|}
\hline $\begin{array}{l}\text { Frame } \\
\text { Control }\end{array}$ & $\begin{array}{c}\text { Message Body 1 } \\
(200400)\end{array}$ & $\begin{array}{c}\text { Message Body 2 } \\
(200401)\end{array}$ & $\begin{array}{c}\text { Message Body 3 } \\
(200402)\end{array}$ & $\begin{array}{c}\text { Message Body 4+ } \\
(200403)\end{array}$ & $\begin{array}{l}\text { Message Body 5 } \\
(200405)\end{array}$ & FCS \\
\hline
\end{tabular}

Fig11.Example of a transfer frame. 


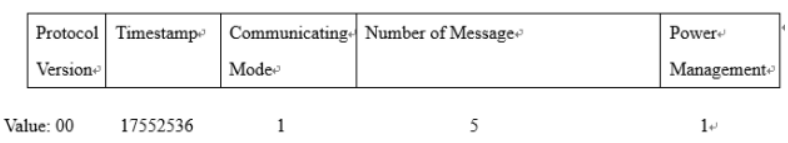

Fig12.Example of a frame control.

\section{Future Work}

This protocol does not contain all the possible methods for indoor and outdoor locating. Also, it does not include all the data that have been used in aforementioned locating method. It is just a framework protocol for sending locating data from the mobile device to the server. It has to be made more completed. Still, the data and frame format for sending calculated location data from the server back to the device are not defined and need to be defined in the future work.

\section{Acknowledgments}

This paper is sponsored by the National Undergraduate Innovation Training Program under grant no. GCCX2014110028. The authors thank Dr. Zhen and Dr. Gao of Chinese Academy of Surveying and Mapping for their constructive suggestions on the designing the protocol.

\section{References}

[1] Pei, Ling, Jingbin Liu, Robert Guinness, Yuwei Chen, T. Kroger, Ruizhi Chen, and Liang Chen. "The evaluation of WiFi positioning in a Bluetooth and WiFi coexistence environment." In Ubiquitous Positioning, Indoor Navigation, and Location Based Service (UPINLBS2012), Oct, 2012, pp. 1-6. IEEE, Helsinki, 2012. Presentation, doi: 10.1109/UPINLBS.2012.6409768.

[2] I. Kraemer, B. Eissfelle, “A-GNSS: A Different Approach”. Inside GNSS, Vol 4, pp. 52-61, September/October 2009.

[3] Yuying Hou, Guoyue Sum, Binwen Fan. "The Indoor Wireless Location Technology Research Based On WiFi,” IEEE International Conference on Natural Computation. 2014, $10^{\text {th }}: 1044-$ 1049, doi: 10.1109/ICNC.2014.6975984.

[4] R. Chen, Y. Chen, L. Pei, W. Chen, H. Kuusniemi, J. Liu, H. Leppäkoski, J. Takala,“A DSPBased Multi-Sensor Multi-Network Positioning Platform," Proceedings of the 22nd International Technical meeting of the Satellite Division of the Institute of Navigation ION GNSS 2009, Savannah, GA, USA, 22-25 September, 2009; pp. 615-621.

[5] [5] Hui Li, Xiangyang Gong. "An Approach to Integrate Outdoor and Indoor Maps for Books Navigation on the Intelligent Mobile Device," Communication Software and Networks (ICCSN), IEEE 3rd International Conference on May 2011, pp. 460-465, doi: 10.1109/ICCSN.2011.6013872.

[6] Yali Jiang, Yuan Fang, Chunlong Yao, Zhisen Wang. “A Design of Indoor \& Outdoor Navigation System," Communication Technology and Application (ICCTA 2011), IET International Conference on Oct. 2011; pp. 877-881.

[7] Sakamoto. Y, Ebinuma. T, Fujii. K, Sugano. S. "GPS-compatible Indoor-positioning Methods for Indoor-outdoor Seamless Robot Navigation,” Advanced Robotics and its Social Impacts (ARSO), 2012 IEEE Workshop on May, 2011. pp. 95-100, doi: 10.1109/ARSO.2012.6213406.

[8] Heng Yang, YaYa Wei, Bing Li, and Dan Guo. "Location Technology.” Beijing: Publishing House of Electronics Industry. 2013.1.

[9] RTCM Special Committee No. 104. RTCM STANDARD 10403.1 For DIFFERENTIAL GNSS (GLOBAL NAVIGATION SATELLITE SYSTEMS) SERVICES - VERSION 3, October 27, 2006. 